this figure and that of the blood under examination is shown above or below this line, according to the numerical excess or deficiency in the average of germs phagocyted by each leucocyte.

It is too early to be able to say whether the temporary benefit which followed the inoculation is likely to be permanent; but the point which I wish to bring out is that the patient's phagocytic power, as gauged by the control blood has varied in direct proportion to the amelioration of his symptoms.

Prior to the date of inoculation I made several examinations of his blood, and found its phagocytic power always lower than the control, but these have not been entered in the chart, as no exact numerical count was made on these occasions. For six days after inoculation it will be noted that his phagocytic power remained considerably lower than the control; during this time he was still having fresh crops of small boils and pimples on his neck. From the seventh to the tenth day he was ree from boils, for the first time for many weeks, and a corresponding rise is seen in his curve. From the eleventh to the thirteenth day a few fresh pimples appeared, which gave him less annoyance than those he usually suffered from, and a similar outcrop occurred towards the end of the period of observation. On both these occasions a drop will be noted in his curve below the level of the control blood.

Without insisting on the uniformity or importance of the phagocytic estimation in this case, which has only been selected as an example of the method, the results appear sufficiently striking to warrant the hope that it may be of service in the investigation of immunity when combined with an estimation of the bactericidal power of the blood fluids.

Since the above note was written I have had the opportunity of examining the phagocytic reaction in another case which was treated eight months ago by Dr. Wright with injections of staphylocuccus vaccine for boils from which the patient had suffered for eight years, and in whose case a permanent cure appears to have been effected. The phagocytic power of the polynuclears was found to be markedly greater than that of the control blood when tested with the strain of staphylococcus, which was originally isolated from one of his boils, and from which the vaccine used in his case was prepared, while the reaction was slightly higher than the control when tested with another variety of staphylococcus.

REFERENCES.

1 Lancet, December rst, rgoo, March 2nd, rgor, and June rst, rgor. 3 Lancet, June Ist, rgor. 4 Proceedings of the Pathological Society, Lancet, March, 23 rd,

\section{EPIDEMIC CATARRHAL JAUNDICE.}

By ELIOT CURWEN, M.B., B.C.CANTAB., Late Physician to the Pekin Hospital.

IN view of the present epidemic outbreak of jaundice in Derbyshire, so well described by Drs. Peck and Kershaw, the following brief notes of the first cases in similar epidemics in Pekin and Tientsin during the winters of $1898-9$ and $1899-1900$ may not be without interest. I have notes of only 44 of the cases seen during the first two months of the epidemic, which, beginning towards the end of October, 1898, lasted well into the spring of the next year; the following winter the epidemic returned, and presented the same features as in the previous year.

The first case seen was on October 22nd, and for some months after this few days passed without, one, two, or three patients coming to the hospital for treatment. Their ages varied from 17 to 60 , and seven times as many men as women applied for treatment. The attack from which one of my students suffered was typical of the series.

On Uctober 27 th and 28 th he told me he felt weak and lethargic. On the evening of the second day he returned to his home feeling sleepy, ate two pears, had pain in the abdomen, and felt sick. At night he was very hot, complained of severe pain in his temples, and his conjunctivæ were, he said, suffused. During the next two days his temperature kept up between $102^{\circ}$ and $102.4^{\circ}$. He felt very weak and ill, and the pain in his temples continued. The administration of calomel (gr.iij) resulted in five dark green motions. On November ist his temperature was down to $96^{\circ}$ in the morning, and the conjunctivæ were slightly yellow for the first time; he was still very weak, and had a pulse of 60 ; there was no tenderness over the liver, or any abdominal discomfort; the tongue was slightly furred. The colour of the conjunctivæ became more marked by November the when he began to complain of itching of the skin; from this date his symptoms gradually improved; ten days later, however, the conjunctivæ were still of a pale lemon colour.

Most of the patients complained of great weakness and of some shortness of breath ; there was generally anorexia, a feeling of abdominal distension, and nausea, and constipation with pale motions was the rule; in 4 cases definite abdominal pain was complained of, but from only 3 did I hear of actual vomiting; diarrhœea occasionally occurred. Another prominent symptom, noted in two-thirds of the cases, was pain in the temples, and this in some cases was described as very severe; it was often accompanied by drowsiness, and in 2 cases by vertigo. More than two-thirds of the patients told me that for the first few days of illness, varying from one to fourteen, they suffered from some degree of fever with shivering, and that as a rule the icteric tint of the conjunctivæ was first noticed the day, or the day after, the fever disappeared. In 5 cases the colour of the conjunctivæ was noted as deep, but in the majority of cases it was a pale straw or lemon colour, and not dark enough to be noticed in the yellow skins of the Chinese; the length of time it lasted was very variable. Only 4 patients complained of pruritus. In 2 cases the liver was noted as slightly enlarged and tender; no albumen was found in any urine examined, but Martin's and Gmelin's reactions were obtained in each case. The pulse was rapidfrom 80 to 128 -in each patient, with the exception of the case narrated above. One man, aged 60 , whose fever had lasted ten days, told me that about the time his conjunctiva became yellow he began to suffer from pains in the muscles of the right arm and in his two ulnar bones; the muscles and bones were still tender on deep pressure when I first saw him five days later.

The affection cannot be very infectious, for I never saw two patients from the same house, and one of my servants who was attacked did not communicate the disease to the other men who slept on the same brick bed; only one patient told me that he had neighbours suffering from the complaint. Some of my patients were severely ill for some days, and, on account of their high fever, weakness, and headache, were thought by their friends to be suffering from typhus fever; others, on the other hand, were affected so slightly that the febrile symptoms, if they existed, passed unnoticed, and they did not know there was anything the matter with them till I handed them a looking glass and told them to look at their eyes.

\section{ENTERIC FEVER IN THE INOCULATED.}

\section{By Major C. BIRT, R.A.M.C. Harrismith, South Africa.}

THE mortality of 947 uninoculated individuals who have suffered from enteric fever in Harrismith, South Africa, from September; 1900, to September, 1901, has been 14.25 per cent. There were 135 deaths among them.

During the same period 263 persons who had been inoculated with typhoid vaccine, for the most part 6 to 18 months previously, contracted this disease. Eighteen of these cases proved fatal. This is equivalent to a death-rate of 6.8 per cent.

The tabulated results of an analysis of 317 charts of the not inoculated and of 151 charts of the inoculated are given below.

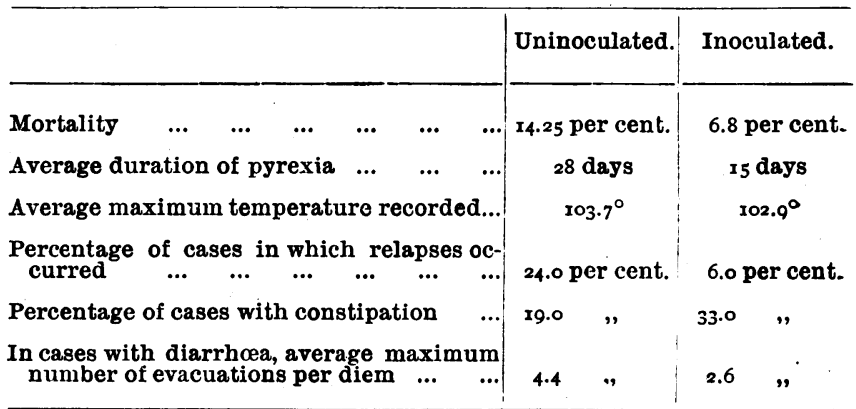

